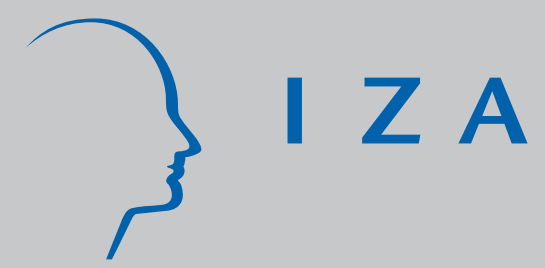

IZA DP No. 6172

The Effect of Religiosity and Religious Festivals on Positional Concerns:

An Experimental Investigation of Ramadan

Alpaslan Akay

Gökhan Karabulut

Peter Martinsson

November 2011 


\title{
The Effect of Religiosity and Religious Festivals on Positional Concerns: An Experimental Investigation of Ramadan
}

\author{
Alpaslan Akay \\ IZA \\ Gökhan Karabulut \\ Istanbul University \\ Peter Martinsson \\ University of Gothenburg
}

Discussion Paper No. 6172

November 2011

\author{
IZA \\ P.O. Box 7240 \\ 53072 Bonn \\ Germany \\ Phone: +49-228-3894-0 \\ Fax: +49-228-3894-180 \\ E-mail: iza@iza.org
}

\begin{abstract}
Any opinions expressed here are those of the author(s) and not those of IZA. Research published in this series may include views on policy, but the institute itself takes no institutional policy positions.

The Institute for the Study of Labor (IZA) in Bonn is a local and virtual international research center and a place of communication between science, politics and business. IZA is an independent nonprofit organization supported by Deutsche Post Foundation. The center is associated with the University of Bonn and offers a stimulating research environment through its international network, workshops and conferences, data service, project support, research visits and doctoral program. IZA engages in (i) original and internationally competitive research in all fields of labor economics, (ii) development of policy concepts, and (iii) dissemination of research results and concepts to the interested public.
\end{abstract}

IZA Discussion Papers often represent preliminary work and are circulated to encourage discussion. Citation of such a paper should account for its provisional character. A revised version may be available directly from the author. 
IZA Discussion Paper No. 6172

November 2011

\section{ABSTRACT \\ The Effect of Religiosity and Religious Festivals on Positional Concerns: An Experimental Investigation of Ramadan*}

This paper examines the effect of religion on positional concerns using survey experiments. We focus on two of the dimensions of religion - degree of religiosity and religious festivals. By conducting the experiments during both the most important day of Ramadan (the Night of Power) and a day outside Ramadan, we find that Ramadan overall has a small and negative impact on positional concerns. Detailed analyses based on the sorting of individuals' degree of religiosity reveal that the decrease in the degree of positional concerns during Ramadan is mainly explained by a decrease in positionality among individuals with a low degree of religiosity. We also discuss the broader welfare implications of our findings.

JEL Classification: C90, D63

Keywords: positional concerns, religion, Ramadan, Islam

Corresponding author:

Peter Martinsson

Department of Economics

University of Gothenburg

P.O. Box 640

40530 Gothenburg

Sweden

E-mail: peter.martinsson@economics.gu.se

\footnotetext{
* Financial support from the Jan Wallander and Tom Hedelius Foundation, from Wilhelm and Martina Lundgrens Science Foundation and from the Swedish Research Council (Vetenskapsrådet) is gratefully acknowledged. We would like to thank Katarina Nordblom for helpful and constructive comments.
} 
"Thou shalt not covet thy neighbor's house; neither shalt thou desire his wife, nor his servant, nor his handmaid, nor his ox... nor any thing that is his"

The book of Exodus (20:17)

“...don't be envious of what I have given to people from my grace and don't enchant your eyes with the blessings and don't put your soul in search of them, because the envious person is unhappy at my blessings that I have distributed among my servants"

Words of Muhammad, Saheeh al-Bukharee

\section{Introduction ${ }^{1}$}

People gain utility not only from their absolute level of income and consumption, but also from their levels of income and consumption relative to those of other people, i.e., positionality (or "status"). Positional concerns have been discussed by many scholars including Veblen (1899/2005) and Duesenberry (1949), but notably also by scholars with different political opinions such as Karl Marx, Adam Smith, and John Stuart Mill. However, as shown by the quote from the Book of Exodus and words from Muhammad, the discussion and awareness of this issue go back thousands of years.

The issue of positionality and its impact on people's behavior has been discussed for a long time among social psychologists (e.g., Festinger, 1954; Suls and Wheeler, 2000). It is argued that the negative impacts of positional concerns on people's welfare are reflected in various feelings. ${ }^{2}$ As discussed in the quotes above, the emotion related to positionality is envy. In our context, it is the feeling that may occur among people when they perceive that others who are comparable to themselves have better living conditions, expressed for example in higher levels of income or consumption. Envy is one of the seven deadly sins in Christianity. In the Quran, the holy book of Islam, envy (al-ghubta

\footnotetext{
${ }^{1}$ In this paper, we focus on Abrahamic religions, i.e., Christianity, Judaism, and Islam, when giving examples to keep the paper compact since it is not a paper on religion per se. However, a future extension of this type of research to other religions is of course important to increase our understanding of positionality.

${ }^{2}$ See, e.g., Elster (1998) for a general discussion on the relationships between economics and emotions, including envy. See also Fischer and Torgler (2006) and Senik (2005).
} 
in Arabic) is in many places presented as one of the most negative human emotions, one that needs to be evaded in order to be a good Muslim. It can therefore be argued that the followers of these major religious teachings may be intrinsically affected and develop different preferences toward positionality or status especially regarding their income or consumption relative to that of others.

Many people around the world are religious, and when also considering people who are affected by religious festivals, almost everybody in the world is to some extent influenced by religion (for an overview of economics of religion, see, e.g., Iannaccone, 1998; Kumar, 2008). ${ }^{3}$ A large body of literature suggests that people’s behavior and emotions might be affected by religion through changes in the socio-economic environment (Emmons and Paloutzian, 2003), for example manifested in more Christians attending church during Christmas and Easter and in the consumption patterns during Christmas, Easter, and Ramadan (Odabasi and Argan, 2009).

The objective of the present paper is to analyze the effect of the degree of religiosity and religious festivals on positional concerns by using a survey experiment approach. Specifically, we conduct our experiment in Turkey, which is a secular but predominantly Muslim country, and we investigate the effect of the degree of religiosity and of the religious festival Ramadan on positionality. We examine positional concerns by using a survey experiment and three different types of goods: (i) income, (ii) working hours, and (iii) car consumption. Income is chosen to create our benchmark results, which can be used in comparisons with previous studies using similar approaches but different locations. In addition, we test for positional concerns toward number of working hours and the value of a car. These two goods are included since it is suggested in the literature that working hours (leisure) is non-positional, while the value of a car is expected to be highly positional. (Alpizar et al., 2005; Boskin and Sheshinski, 1978; Carlsson et al., 2007; Carlsson et al., 2009; Frank, 1999; Ireland, 2001; Ljungqvist and Uhlig, 2000; Solnick and Hemenway, 2005;).

\footnotetext{
${ }^{3}$ For example, Iannaccone (1998) reports that American church membership and church attendance have risen in the last century, and that almost $95 \%$ of Americans believed in God at the time of his study.
} 
During the last two decades, positional concerns have been empirically investigated by using either subjective well-being data (e.g., Akay and Martinsson, 2011; Clark and Oswald, 1996; Clark et al., 2008; Ferrer-i-Carbonell, 2005; Luttmer, 2005; McBride, 2001; Senik, 2004, 2009) or survey experiments (e.g., Alpizar et al., 2005; Carlsson et al., 2007; Frank and Sunstein, 2001; Lampi and Nordblom, 2010; Pingle and Mitchell, 2002; Solnick and Hemenway, 1998). In the subjective well-being approach, positional concerns are analyzed in a regression framework (see, e.g., a discussion in van Praag and Ferrer-i-Carbonell, 2008), where subjective well-being (measured as "happiness" or "life satisfaction”) is explained by an individual's absolute level of income and her income relative to the average income of the people in her reference (comparison) group while controlling for other factors that might influence subjective well-being. ${ }^{4}$ Then, the estimated coefficient of the relative income variable is a measure of the impact of positional concerns. On average it is found to be significantly negative, implying the existence of positional concerns (e.g., Clark et al., 2008; Luttmer, 2005; McBride, 2001; Senik, 2004; 2009). ${ }^{5}$

The survey experiment is most commonly based on repeated hypothetical questions to elicit the degree of positional concerns of individuals, or more correctly the degree of positional concerns is elicited within a range rather than as an exact value (e.g., Carlsson, et al., 2007; Johansson-Stenman et al., 2002; Solnick and Hemenway, 1998). The general design of survey experiments is that subjects make repeated pairwise choices between two alternatives. In each choice situation, the two alternatives are described to the

\footnotetext{
${ }^{4}$ One important issue in the subjective well-being approach is that the actual reference group of an individual is unknown. In the analyses, an individual's reference group is therefore assumed (e.g., Ferrer-iCarbonell, 2005). Clark and Senik (2010) use a novel approach by directly asking people about their reference groups, which are then used in their analyses. However, this is not an issue in survey experiments since the reference group is clearly stated in the experiment design.

${ }^{5}$ Some studies using subjective well-being data have identified a positive effect of relative income on people's subjective well-being (Bookwalter and Dalenberg, 2009; Kingdon and Knight, 2007; Senik, 2005). The positive effects of positional concern are interpreted as a type of tunnel-effect or altruism (Hirschman and Rothschild, 1973). The information about the income level of other people may be interpreted to signal future prosperity. This signal effect is found especially in transition economies where income mobility is higher (Ravillon and Lokshin, 2000). The other possible interpretation is altruism, although this effect is considered to prevail for poor, small societies with tight social connections (Kingdon and Knight, 2007).
} 
subjects in terms of their own level of income or consumption and the average level of income or consumption among others in a specific group. Since each subject makes repeated choices, it is possible to calculate the degree of positional concern within an interval, where the length of the interval depends on the number of questions asked.

A number of survey experiments suggest that people do have positional concerns, but that the degree of positional concerns differs across locations and types of goods. Positional concerns among people result in welfare loss, and this has been discussed for example in relation to saving patterns, wage formation, and labor supply behavior of individuals (e.g., Agell and Lundborg, 2003; Duesenberry, 1949; Neumark and Postleweit, 1998). Moreover, an interesting application of these results is in the discussion on optimal taxation, and for example Aronson and Johansson-Stenman (2008) and Blomquist (1993) analyze theoretically how to incorporate appropriate adjustments into the optimal tax rules to reduce welfare losses from positional concerns.

To test the effect of a religious festival and degree of religiosity on positional concerns, we conduct survey experiments in Turkey. ${ }^{6}$ We select Ramadan as the religious festival and conduct the first experimental session in the early morning of the Night of Power (Leylat al-Qadr), which is the most important day during Ramadan for Muslims. Ramadan lasts 29-30 days and the Night of Power is on the $27^{\text {th }}$ day of the month of Ramadan. It is mentioned in the Quran that spending this night praying is "better than one thousand months”7 (Quran, 92: Qadr). As a result, the religious activities peak during the daytime and the nighttime of this day.

There are important social and psychological aspects of Ramadan and fasting, and these have long been discussed by Islamic scholars. Generally, they indicate that the aim of fasting is to improve the person's empathy for others, sharing, kindness, generosity, and forgiveness (see, e.g., Kahn, 1997). Fasting is a highly demanding prayer that includes strict avoidance of fluids and nourishment from dawn (sahur) to dusk (iftar), and this is

\footnotetext{
${ }^{6}$ In the 2001 World Value Survey, 99\% proclaimed themselves to be Muslims in Turkey.

${ }^{7}$ However, this does not mean that prayers during the rest of the year can be substituted since the five daily prayers (Salat) comprise one of the five basic acts that are mandatory for each Muslim.
} 
obligatory for every Muslim who has reached puberty and is capable of making rational judgments (Quran, 2:183-84). Fasting is the major form of prayer in Ramadan, and we use the degree of fasting as a proxy for the degree of religiosity. To be able to compare the positional concerns during Ramadan to those outside Ramadan, we also conducted another identical experimental session two months after Ramadan on a day during a period of only daily prayers and no religious festivals. We conducted both experimental sessions in the early morning to avoid the potential effect of hunger on behavior during Ramadan. Thus, our specific design allows us to disentangle the effects of the religious festival and the degree of religiosity on individual's positional concerns toward different goods.

Our results show that the subjects exhibit levels of positional concerns both during and outside Ramadan that are similar to the levels observed in Western countries. Positional concerns during Ramadan are however lower than outside Ramadan, which is expected given the environment surrounding Ramadan with its emphasis on the negative impact of envy and importance of empathy and sharing. The low religious people show stronger positionality concerns outside Ramadan, while high religious people are pretty much unaffected, and this explains the overall change in concerns during and outside Ramadan. Thus, our findings point to the fact that religious festivals affect people with lower degrees of religiosity, or alternatively people with lower degrees of religiosity change their behavior according to what is expected during the religious festival.

The remaining part of the paper is organized as follows: In the next section we introduce our tailor-made survey-experiment design and in Section 3 we present the results including a detailed analysis of positional concerns separated into degree of religiosity and religious festival. Finally, Section 4 concludes the paper.

\section{The survey experiment}

We conducted two experimental sessions, one during the morning of the Night of Power during Ramadan and the other outside Ramadan during a time with no religious festivals 
except the regular daily prayers, and this was the only difference between the way the experimental sessions were conducted. In the experiment, we investigated positional concerns for three different types of goods: (i) income, (ii) working hours (or leisure), and (iii) the consumption value of a car. In our experimental design, we first assume the following utility function for individual $i$ :

$$
U_{i}\left(y_{i}, y_{i}-\bar{y}_{s}^{r}\right)=(1-\gamma) y_{i}+\gamma\left(y_{i}-\bar{y}_{s}^{r}\right),
$$

where $U_{i}$ indicates the utility of individual $i, y_{i}$ is the absolute level of income of individual $i$, and $\bar{y}_{s}^{r}$ is the income level of other people in the society $s^{8}$ The parameter $\gamma$ shows the proportion of a change in utility that comes from an increase in relative income.

The design of our survey experiment follows Johansson-Stenman et al. (2002) and Alpizar et al. (2005). In the survey, we described that the subjects were about to make choices for their imaginary future relative, who would be living two generations into the future. The main reason why we phrased the scenario in terms of a future relative was to disregard the subject's own circumstances and environment when conducting the experiment (see a discussion on this issue in Johansson-Stenman et al., 2002). The subjects were asked to choose the society that they thought would be in the best interest of their grandchild. The respondents were also reminded not to choose what they considered to be best for society, but only what would be best for their grandchild. The survey consisted of three parts: (i) main instructions, (ii) an example, and (iii) the experiment. The main scenario and the nine different choice situations are presented in the Appendix.

Figure 1 below presents an example question that was presented after the main instruction. The example focused on income, which was the first good in our survey, to

\footnotetext{
${ }^{8}$ An alternative specification is to use a ratio utility function, i.e., $U\left(y_{i}, y_{i} / \bar{y}_{s}^{r}\right)$, yet this specification results in a similar degree of positionality, and hence the effect on the overall results is unaffected (e.g., Alpizar et al., 2005).
} 
illustrate the choice situations to come. In each choice situation, there were two societies $\mathrm{A}$ and $\mathrm{B}$, and the subject was asked to choose one of them. The societies in the choice situations were identical except that the levels of the goods (income, working hours, and value of a car) were changed for the imaginary relative in order to facilitate calculation of marginal degree of positionality. It was also stressed that the prices of the goods were the same as the actual levels in both societies at the time of the survey.

\section{Figure 1 about here}

If a respondent is indifferent between the two societies presented in a choice situation, then we know that $y_{i, A}-\gamma \bar{y}_{A}^{r}=y_{i, B}-\bar{y}_{B}^{r}$. By using this, we can then calculate the degree of positional concern from the above example as

$$
\gamma=\frac{y_{i, A}-y_{i, B}}{\bar{y}_{A}^{r}-\bar{y}_{B}^{r}}=\frac{2000-1800}{2500-1500}=0.20
$$

Thus, if a respondent is indifferent between the two societies presented in Figure 1, then the marginal degree of positional concern, $\gamma$, is equal to 0.20 . If the respondent chose society A (in which the relative income position of the imaginary future relative is better than in society B), then $\gamma<0.20$, and vice versa. Each respondent was asked to make repeated choices between the two societies, which allows us to calculate the degree of positional concern within an upper and lower bound.

The complete experimental design is summarized in Table 1. The first block describes the design used to investigate positional concerns for income, and the table is read as follows. The first choice situation consists of a choice between society A (absolute income is 2,000 Turkish lira, TRY, ${ }^{9}$ and others' average income is 2,200 TRY) and society B(1) (absolute income is 1,750 TRY and others' income is 1,290 TRY). If a subject is

\footnotetext{
${ }^{9}$ The exchange rate at the time of the experiments were 1.48 TRY $=1$ USD and 1.42 TRY $=1$ USD, respectively. The price levels are chosen as realistic as possible by considering average wage rates in Turkey.
} 
indifferent between these two societies, then the marginal degree of positionality is 0.28 , as shown in the table. If society $\mathrm{A}$ is chosen, then the marginal degree of positionality is lower than 0.28 , and vice versa. In the second choice situation, which is between society $\mathrm{A}$ and society $\mathrm{B}(2)$, the marginal degree of positionality is equal to 0.52 if the subject is indifferent between society $\mathrm{A}$ and $\mathrm{B}(2)$, etc. Thus, it is possible to set an upper and a lower bound on the marginal degree of positionality for an individual. The same survey design and interpretation for the choice situations relating to leisure and value of the car as for income are presented in Table 1.

\section{Table 1 about here}

We conducted the survey experiments at two different points in time, i.e., (i) on the most important day of Ramadan - the Night of Power - and (ii) on a day outside Ramadan, and subjects only participated in one of the two sessions, i.e., a between-subject design. The location of the experiment was a huge lecture hall with a capacity of 250 people to ensure enough space and privacy between the subjects. Both experiments were conducted in the same place and with the same assistants to avoid any confounding effects. In a postexperimental questionnaire, we collected information about socio-demographic and economic information. It is not easy to identify an individual's degree of religiosity, and since no objective measure to elicit this information exists, we need a proxy. We chose the degree of fasting as proxy, believing that this is a better proxy than self-reported degree of religiosity or religious attendance in a mosque. First of all, fasting is a demanding form of praying since it requires strict avoidance of fluids and nourishment from dawn to dusk. Second, asking about days of fasting stands out less than asking questions directly related to degree of religiosity, especially in a country like Turkey where such questions are somewhat politically sensitive. The subjects were then classified into two groups of religiosity depending on their degree of fasting. Only subjects who spent the whole Ramadan fasting are classified as having a high degree of religiosity (30 days for males and 25 days for females since the latter are exempted from 
fasting during menstruation). The remaining subjects, i.e., those who did not fast all days, are classified as having a low degree of religiosity. ${ }^{10}$

\section{Results}

In total, 180 subjects participated in our two experimental sessions. We will begin by investigating for each good separately whether the subjects responded to the choice situations in a consistent way. The design of the experiment is such that a subject is expected to choose alternative $\mathrm{A}$ in a choice situation when the implicit marginal degree of positionality in the choice situation is higher than her own marginal degree of positionality. In the experiment, each subsequent choice situation for a specific good assumes a higher degree of positionality, and thus a subject is considered to have answered inconsistently if she ever chose alternative B after having chosen alternative A in an earlier choice situation for the same good (this conflicts with the monotonicity assumption of the utility). Approximately 20 subjects in each experimental session for the three goods are classified as inconsistent, and thus we have, depending on the good, a total sample of $130-140$ subjects.

Table 2 presents both the proportion of the subjects who chose society B in each choice situation, i.e., the proportion of subjects with a degree of positionality that at least corresponds to indifference in the specific choice situation, and the calculated mean degree of positionality for each good. Table 2 separates the results by religious festival (Ramadan and non-Ramadan), degree of religiosity (low and high), and type of goods. For each good, there are three different questions. In Table 2, the rows for choice situation should be read as follows: In the upper left corner, the value 0.44 is stated. This means that in the first choice situation in the income experiment conducted during Ramadan, with an implicit marginal degree of positionality of $0.28,44 \%$ of the subjects classified as low religious subjects chose society B (implying that $56 \%$ chose society A, in which the absolute income is higher). Thus, this result can be interpreted as $44 \%$ of the

\footnotetext{
${ }^{10}$ We use the labels "low" and "high" to differentiate between different degrees of religiosity. It would be more accurate to label the "low" group as "low and medium," but for simplicity we decided to write only "low."
} 
subjects having an implicit degree of positionality that is at least equal to 0.28 . The proportions of the subjects who chose society B gradually decrease in the subsequent choice situations as the implicit marginal degree of positionality increases from 0.28 to 0.52 and then to 0.73 resulting in $43 \%$ and $35 \%$ of the low religious subjects choosing society B in these choice situations during Ramadan. The interpretation is similar for the other choice situations presented in Table 2. Overall, a large number of subjects chose society B in the first choice situation for each good, reflecting some degree of positional concern. As expected, there seems to be a higher degree of positionality for a luxury car than for income and working hours, which is expected. In a preliminary comparison between religious festivals and degree of religiosity, the key finding seems to be that people with a low degree of religiosity are less likely to choose society B during Ramadan compared to outside Ramadan, i.e., they show a lower degree of positionality during Ramadan.

Table 2 also shows the results of the test of the hypothesis of equal proportions of individuals who chose society B, separated by festival and religiosity. We report the pvalues of the test of equality of proportions based on Mann-Whitney U tests. In the four main combinations of tests (i.e., degree of religiosity and religious festivals), we report tests of (i) no religious festival effect among people with a low degree of religiosity, (ii) no religious festival effect among people with a high degree of religiosity, (iii) no religiosity effect among low and high religiosity people during Ramadan and (iv) no religiosity effect among low and high religiosity people outside Ramadan. We find significant differences at the $5 \%$ level in several of the choice situations between the proportions of low religious subjects who chose Society B during Ramadan and outside Ramadan, except for in the case of luxury car consumption.

\section{Table 2 about here}

To make our results directly comparable to previous studies, we also estimate the mean marginal degree of positionality split by religious festival (Ramadan and non-Ramadan) and degree of religiosity (high and low degree of religiosity) by using a non-parametric 
estimator that is robust in the sense that it does not rely on any parametric assumption. To obtain the mean values we use the Spearman-Karber estimator, and this is given as ${ }^{11}$

$$
M M D P_{S K}=\sum_{k=1}^{4} \frac{\left(t_{k}+t_{k+1}\right)\left(P_{k}-P_{k+1}\right)}{2}
$$

where $t_{k}$ is the implicit marginal degree of positionality for the choice situation $k=1,2,3$, 4; and $P_{k}$ is the actual proportion of the subjects who selected society B in the $k$ th choice situation. $^{12}$ The estimated mean degree of positionality with the Spearman-Karber estimator is also presented in Table 2, together with the 95\% confidence intervals. As expected from the descriptive statistics, we find a higher degree of positional concern for income and car consumption than for working hours. Moreover, there are differences across religious festivals, yet the impact of degree of religiosity is only slightly different. By and large, the estimated mean degrees are similar to those found in other studies. For example, Carlsson et al. (2007) estimated MMDP for income to be around 0.59-0.71, using a similar experiment with a random sample of the population in Sweden. Alpizar et al. (2005) estimated the same degree of positionality for income as 0.45 , using a sample of Costa Rican university students. The relationships between our three goods in terms of degree of positionality are similar to those reported in Alpizar et al. (2005).

Moreover, we estimate a parametric model and control for some socio-demographic and economic characteristics of subjects to check the sensitivity of previous findings. To this end, interval regression is used by considering that the dependent variable is an interval (lower and upper bounds) of different implicit marginal degrees of positionality. The bounds used in the regression are the same as those used in the non-parametric analyses

\footnotetext{
${ }^{11}$ An alternative is the Kaplan-Meier-Turnbull estimator, which by construction results in a lower mean degree of positionality due to the conservative way of treating the proportion of subjects with a degree of positionality between the points included in the experiments.

${ }_{12}$ In order to calculate the $95 \%$ confidence intervals, we need to calculate the standard errors. The variance of the Spearman-Karber estimator is calculated as $\operatorname{Var}\left[M M D P_{S K}\right]=\sum_{k=2}^{4} \frac{\left(t_{k+1}+t_{k-1}\right)^{2} P_{k}\left(1-P_{k}\right)}{4\left(N_{k}-1\right)}$, where $N_{k}$ is the number of the respondent in the kth choice situation. Note that the first and the last choice situations are assumed as having 0 and 1 implicit degree of positionality.
} 
above (the marginal degree of positionality found in Table 1), and for the extreme values the bounds are set to 0 and 1 . We control for festival time and degree of religiosity by using three interaction terms with non-Ramadan and low degree of religiosity as reference group. The results of the analysis are presented in Table 3.

\section{Table 3 about here}

Consistent with previous results, the parametric estimator also suggests a small impact of religious festivals and religiosity on positional concerns. We find significant differences only for the case of income. More exactly, we find that the subjects with a low degree of religiosity surveyed during Ramadan show significantly lower positional concerns compared to subjects with a low degree of positionality outside Ramadan. Other than that, none of the pairwise comparison of the estimated parameters of interaction terms differ significantly. The marginal degree of positionality can also be estimated using the linear predictions after the estimation of the interval regressions, conditional on the sociodemographic variables. Our calculations show that the results produced by the interval regression are almost identical to the results presented above with the Spearman-Karber estimator, with the only difference being that the confidence intervals obtained with the interval regression are slightly larger. ${ }^{13}$

\section{Conclusions}

The emerging literature on empirical tests of positionality confirms that positionality exists, but that the degree of positionality varies across goods and locations. However, differences within a location and the effect of socio-demographic circumstances and social environment remain poorly investigated, partly because students have been used. A notable exception is Carlsson et al. (2007), who used a random sample of Swedes. The present paper aimed to test whether there is an effect of religious festivals and degree of religiosity on the positional concerns of individuals using two experimental sessions conducted during and outside the Ramadan month respectively. We analyzed

\footnotetext{
${ }^{13}$ The results are available upon request.
} 
positionality for three goods: income, working hours (or leisure time), and car consumption.

The results suggest that the subjects showed a substantial degree of positionality for each good, and as expected the lowest degree for working hours. Overall, the findings are similar to those in previous studies. Nonparametric and parametric analyses indicated, along the same lines, little statistical evidence of an effect of the analyzed religious festivals and religiosity on the degree of positionality although there are differences in magnitude. As expected according to religious doctrines, the positionality was lower during Ramadan. Moreover, the results suggest that people with a high degree of religiosity were unaffected by religious festivals, while people with a low degree of religiosity had a lower degree of positionality during the religious festival. This is expected since people with a high degree of religiosity are supposed to follow religious doctrine not only during Ramadan, but also during the rest of the year. Hence, there is no effect of the studied religious festival on the positional concerns of people who are highly religious. Given that envy is discussed in many places in the Quran, and that it should be evaded in order to be a good Muslim, it does not come as a surprise that less religious individuals are affected by a religious festival.

In a broader perspective, there are interesting welfare implications of our findings, since the welfare loss of redistribution of resources during Ramadan is smaller than outside Ramadan. This is, as discussed above, explained by changed behavior among less religious people. Given the importance of festivals found in this paper, it would be interesting to find out the applicability to other festivals and activities that may induce changes in people's attitudes toward others by, e.g., inducing empathy. For example, larger aid festivals (e.g., Live Aid in 1985) and charitable fundraisers for victims of natural disasters such as the Tsunami in Thailand in 2004 are successful in raising money, and this can at least partly be explained by changes in positional concerns. Thus, an important area for future research is to try to understand in which situations the welfare loss in case of redistribution is lower, or alternatively when to impose taxation on people to reduce the welfare losses for contributors. 


\section{References}

Agell, J. and P. Lundborg (2003). Survey Evidence on Wage Rigidity and Unemployment: Sweden in the 1990s. Scandinavian Journal of Economics 105: 15-29.

Akay, A. and P. Martinsson (2011). Does Relative Income Matter for the Very Poor? Evidence from Rural Ethiopia. Economics Letters 110: 213-215.

Alpizar, F., F. Carlsson, and O. Johansson-Stenman (2005). How Much Do We Care about Absolute versus Relative Income and Consumption? Journal of Economic Behavior and Organization 56: 405-421.

Aronsson, T. and O. Johansson-Stenman (2008). When the Joneses' Consumption Hurts: Optimal Public Good Provision and Nonlinear Income Taxation. Journal of Public Economics 92: 986-997.

Bookwalter, J. and D.R. Dalenberg (2009). Relative to What or Whom? The importance of Norms and Relative Standing, World Development 38: 345-355.

Blomquist, S. (1993). Interdependent Behavior and the Effect of Taxes. Journal of Public Economics 51: 211-218.

Boskin, M. J. and E. Sheshinski (1978). Optimal redistributive taxation when individual welfare depends upon relative income. Quarterly Journal of Economics 92: 589601.

Carlsson, F., G. Gupta and O. Johansson-Stenman, (2009). Keeping up with the Vaishyas? Caste and Relative Standing in India. Oxford Economic Paper 61: 5273.

Carlsson, F., O. Johansson-Stenman, and P. Martinsson (2007). Do You Enjoy Having More than Others? Survey Evidence of Positional Goods. Economica 74: 586598.

Clark, A. E., P. Frijters, and M.A. Shields (2008). Relative Income, Happiness, and Utility: An Explanation for the Easterlin Paradox and Other Puzzles. Journal of Economic Literature 46: 96-144.

Clark, A. E. and A. J. Oswald (1996). Satisfaction and Comparision Income. Journal of Public Economics 61: 359-381.

Clark, A. E. and C. Senik (2010). Who compares to whom? The anatomy of income comparison in Europe. Economic Journal 120, 573-594.

Duesenberry, J. S. (1949). Income, Saving, and the Theory of Consumer Behavior. Cambridge, Mass: Harvard University Press. 
Elster, J. (1998). Emotions and economics. Journal of Economic Literature 36: 47-74.

Emmons, R.A. and R.F. Paloulzian (2003). The Psychology of Religion. Annual Review of Psychology 54: 377-402.

Ferrer-i-Carbonell, A. (2005). Income and Well-Being: An Empirical Analysis of the Comparison Income Effect. Journal of Public Economics 89: 997-1019.

Festinger, L. (1954). A theory of social comparison, Human Relations 7, 117-140.

Fischer, J. A. V. and B. Torgler (2006). The Effect of Relative Income Position on Social Capital. Economics Bulletin 26: 1-20.

Frank, R.H. (1999). Luxury Fever: Money and Happiness in an Era of Excess. New Jersey: The Free Press.

Frank, R.H. and C.R. Sunstein (2001). Cost-Benefit Analysis and Relative Position. University of Chicago Law Review 68: 323-374.

Hirschman, A. O. and M. Rothschild (1973). The changing tolerance for income inequality in the course of economic development. Quarterly Journal of Economics 87: 544-566.

Iannaccone, L. R. (1998). Introduction to the economics of religion. Journal of Economic Literature 36: 1465-1495.

Ireland, N. J. (2001). Optimal income tax in the presence of status effects. Journal of Public Economics 81: 193-212.

Johansson-Stenman, O., F. Carlsson, and D. Daruvala (2002). Measuring Future Grandparents' Preferences for Equality and Relative Standing. Economic Journal 112: 362-383.

Kingdon, G. and J. Knight (2007). Community, comparisons and subjective well-being in a divided society. Journal of Economic Behavior and Organization 64: 69-90.

Kahn, M.M. (1997). Sahih al-Bukhari: The Translation of the Meanings (9 Volume set) Dar-us-Salam Publications.

Kumar, V. (2008). A critical review of economic analyses of religion, IGIDR Working Paper Series 2008-023.

Lampi, E. and K. Nordblom (2010). Money and success - Sibbling and birth-order effects on positional concerns. Journal of Economic Psychology 31: 131-142.

Ljungqvist, L. and H. Uhlig (2000). Tax policy and aggregate demand management under catching up with the Joneses. American Economic Review 90: 356-66.

Luttmer, E. F. P. (2005). Neighbors as Negatives: Relative Earnings and Well-Being. The Quarterly Journal of Economics 120: 963-1020. 
McBride, M. (2001). Relative-Income Effects on Subjective Well-Being in the CrossSection. Journal of Economic Behavior and Organization 45: 251-278.

Neumark, D. and A. Postlewait (1998). Relative Income Concerns and the Rise in Married Women's Employment. Journal of Public Economics 70: 157-83.

Odabasi, Y and M. Argan (2009). Aspects of Underlying Ramadan Consumption Patterns in Turkey. Journal of International Consumer Marketing 21: 203-218.

Pingle, M. and M. Mitchell (2002). What motivates positional concerns for income? Journal of Economic Psychology 23: 127-148.

Ravillon, M. and M. Lokshin (2000). Who Wants to Redistribute? The Tunnel-Effect in 1990s Russia. Journal of Public Economics 76: 87-104.

Schimmel, S. (1997). The Seven Deadly Sins: Jewish, Christian, and Classical Reflections on Human Psychology. Oxford: Oxford University Press.

Senik, C. (2004). When Information Dominates Comparison: Learning from Russian Subjective Panel Data. Journal Public Economics 88: 2099-2123.

Senik, C. (2005). Income distribution and well-being: what can we learn from subjective data? Journal of Economic Surveys 19: 43-63.

Senik, C. (2009). Direct Evidence on Income Comparisons and Their Welfare Effects. Journal of Economic Behavior and Organization 72: 408-424.

Solnick, S. and D. Hemenway (1998). Is More Always Better? A Survey on Positional Concerns. Journal of Economic Behavior and Organization 37: 373-383.

Solnick, S., and D. Hemenway, (2005) Are Positional Concerns Stronger in Some Domains than in Others? American Economic Review 95, 147-151.

Suls, J. and L. Wheeler (2000). Handbook of Social Comparison. New York: Kluwer Academic Publishing Corp.

van Praag, B. M. S. and A. Ferrer-i-Carbonell (2008). Happiness Quantified: A Satisfaction Calculus Approach. Oxford University Press.

Veblen, T. (1899/2005). The Theory of the Leisure Class. Digireads.com. 


\title{
Appendix: Instructions in the survey experiment.
}

\author{
About your future relative... \\ Example: \\ In the example below, your future relative earns 200 TYR more in society A compared to in society B. You \\ can also see that your future relative earns $500 \mathrm{TYR} / \mathrm{month}$ less than the average income in society A and \\ $300 \mathrm{TYR} / \mathrm{month}$ more than the average income in society B.

$$
\begin{array}{ll}
\text { Society A } & \text { - Your relative's income is } 2,000 \mathrm{TYR} / \mathrm{month} \text { after tax. } \\
& - \text { The average income in society is } 2,500 \mathrm{TYR} / \mathrm{month} \text { after tax. } \\
\text { Society B } & - \text { Your relative's income is } 1,800 \mathrm{TYR} / \mathrm{month} \text { after tax. } \\
& \text { - The average income in society is } 1,500 \mathrm{TYR} / \mathrm{month} \text { after tax. }
\end{array}
$$

Please choose which society you consider to be the best one for your future relative, that is, the society in which your future relative will be most content. It is important that you focus your answer solely on this. That is, which society is the best for your future relative? You should not consider which society is best overall.

\section{Income Experiment}

\section{Question 1 Income for your future relative (1)}

Choose between society A and B for your future relative.

Society A - Your relative’s income is 2,000 TYR/month after tax.

- The average income in society is 2,200 TYR/month after tax.

Society B - Your relative's income is 1,750 TYR/month after tax.

- The average income in society is 1,290 TYR/month after tax.

Everything else is the same in the two societies, including the price level. In both society A and B, your relative works 40 hours per week, which is same as the average number of working hours. Choose the society that you consider to be the best for your future relative.

\section{$\square$ Society A}

\section{$\square$ Society B}

\section{Question 2 Income for your future relative (2)}

Choose between society A and B for your future relative.

Society A - Your relative's income is 2,000 TYR/month after tax.

- The average income in society is $2,200 \mathrm{TYR} / \mathrm{month}$ after tax.

Society B - Your relative's income is 1,500 TYR/month after tax.

- The average income in society is $1,237 \mathrm{TYR} /$ month after tax. 
Everything else is the same in the two societies, including the price level. In both society A and B, your relative works 40 hours per week, which is same as the average number of working hours. Choose the society that you consider to be the best for your future relative.

\section{$\square$ Society A}

$\square$ Society B

\section{Question 3 Income for your future relative (3)}

Choose between society A and B for your future relative.

Society A - Your relative's income is 2,000 TYR/month after tax.

- The average income in society is 2,200 TYR/month after tax.

Society B - Your relative's income is 1,260 TYR/month after tax.

- The average income in society is $1,188 \mathrm{TYR} / \mathrm{month}$ after tax.

Everything else is the same in the two societies, including the price level. In both society A and B, your relative works 40 hours per week, which is same as the average number of working hours. Choose the society that you consider to be the best for your future relative.

$\square$ Society A

$\square$ Society B

\section{Working hours experiment}

\section{Question 4 \\ Working hours and leisure for your future relative}

Choose between society A and B for your future relative. The societies are the same except for the information given below.

Society A • Y Your relative’s working hours are 40 hours per week.

- Average working hours are 36 hours per week.

Society B - Y Your relative’s working hours are 42.5 hours per week.

- Average working hours are 46 hours per week.

Everything else is the same in the two societies, including the price level. In both society A and B, your relative's monthly income is 2,000 TYR, which is the same as the average income. Choose the society that you consider to be the best for your future relative.

$\square$ Society A

$\square$ Society B 


\begin{tabular}{l} 
Question 5 Working hours and leisure for your future relative \\
\hline Choose between society A and B for your future relative. The societies are the same except for the \\
information given below.
\end{tabular}

$\begin{array}{ll}\text { Society A } & \text { - Your relative’s working hours are } 40 \text { hours per week. } \\ & \text { - Average working hours are } 36 \text { hours per week. } \\ \text { Society B } & \text { - Your relative's working hours are } 47 \text { hours per week. } \\ & \text { - Average working hours are } 51 \text { hours per week. }\end{array}$

Everything else is the same in the two societies, including the price level. In both society A and B your relative's monthly income is 2,000 TYR, which is the same as the average income. Choose the society that you consider to be the best for your future relative.

\title{
$\square$ Society A \\ $\square$ Society B
}

\begin{abstract}
Question6 Working hours and leisure for your future relative
Choose between society A and B for your future relative. The societies are the same except for the information given below.

$\begin{array}{ll}\text { Society A } & \text { • Your relative's working hours are } 40 \text { hours per week. } \\ & \text { • Average working hours are } 36 \text { hours per week. } \\ \text { Society B } & \text { - Your relative's working hours are } 61 \text { hours per week. } \\ & \text { - Average working hours are } 64 \text { hours per week. }\end{array}$

Everything else is the same in the two societies, including the price level. In both society A and B your relative's monthly income is 2,000 TYR, which is the same as the average income. Choose the society that you consider to be the best for your future relative.
\end{abstract}

$\square$ Society A

$\square$ Society B

\section{Car consumption experiment}

\section{Question 7}

\section{Market value of the car for your future relative}

Choose between society A and B for your future relative. The societies are the same except for the information given below. This means the consumption of all other goods is the same in both societies even if the market value of cars is higher in one society. The company at which your relative works provides a company car.

Society A

- Your relative's company car is a few years old with a market value of 30,000 TYR.

- The average market value of cars in the society is 33,000 TYR 
- Your relative's company car is a few years old with a market value of 28,000 TYR

- The average market value of cars in the society is 25,036 TYR

Everything else is the same in the two societies, including the price level and your relative's income. Choose the society that you consider the best for your future relative.

\title{
$\square$ Society A
}

$\square$ Society B

\begin{abstract}
Question 8 Market value of the car for your future relative
Choose between society A and B for your future relative. The societies are the same except for the information given below. This means the consumption of all other goods is the same in both societies even if the market value of cars is higher in one society. The company at which your relative works provides a company car.
\end{abstract}

Society A

- Your relative's company car is a few years old with a market value of 30,000 TYR.

- The average market value of cars in the society is 33,000 TYR

Society B - Your relative's company car is a few years old with a market value of 25,000 TYR

- The average market value of cars in the society is 22,904 TYR

Everything else is the same in the two societies, including the price level and your relative's income. Choose the society that you consider the best for your future relative.

\section{$\square$ Society A}

$\square$ Society B

Question 9 Market value of the car for your future relative

Choose between society A and B for your future relative. The societies are the same except for the information given below. This means the consumption of all other goods is the same in both societies even if the market value of cars is higher in one society. The company at which your relative works provides a company car.

Society A

Society B
- Your relative's company car is a few years old with a market value of 30,000 TYR.

- The average market value of cars in the society is 33,000 TYR

- Your relative's company car is a few years old with a market value of 22,000 TYR

- The average market value of cars in the society is 21,829 TYR

Everything else is the same in the two societies, including the price level and your relative's income. Choose the society that you consider the best for your future relative.

$\square$ Society A

$\square$ Society B 
Table 1. Experimental design (for both Ramadan and non-Ramadan experiments)

\begin{tabular}{|c|c|c|c|}
\hline & $\begin{array}{c}\text { Own } \\
\text { Income etc. }\end{array}$ & $\begin{array}{c}\text { Average } \\
\text { Income etc. }\end{array}$ & $\begin{array}{c}\text { Implicit marginal } \\
\text { degree of } \\
\text { positionality }\end{array}$ \\
\hline \multicolumn{4}{|c|}{ Income experiment: TRY/Month } \\
\hline Society A & 2,000 & 2,200 & \\
\hline Question 1: Society B (1) & 1,750 & 1,290 & 0.28 \\
\hline Question 2: Society B (2) & 1,500 & 1,237 & 0.52 \\
\hline Question 3: Society B (3) & 1,260 & 1,188 & 0.73 \\
\hline \multicolumn{4}{|c|}{ Leisure experiment, working hours/week } \\
\hline Society A & 40 & 36 & \\
\hline Question 4: Society B (1) & 42.5 & 46 & 0.25 \\
\hline Question 5: Society B (2) & 47 & 51 & 0.50 \\
\hline Question 6: Society B (3) & 61 & 64 & 0.75 \\
\hline \multicolumn{4}{|c|}{ Car consumption experiment, market value in TRY } \\
\hline Society A & 30,000 & 33,000 & \\
\hline Question 7: Society B (1) & 28,000 & 25,036 & 0.25 \\
\hline Question 8: Society B (2) & 25,000 & 22,904 & 0.50 \\
\hline Question 9: Society B (3) & 22,000 & 21,829 & 0.75 \\
\hline
\end{tabular}


Table 2. Descriptive results and tests of hypotheses by religious festival, religiosity and goods

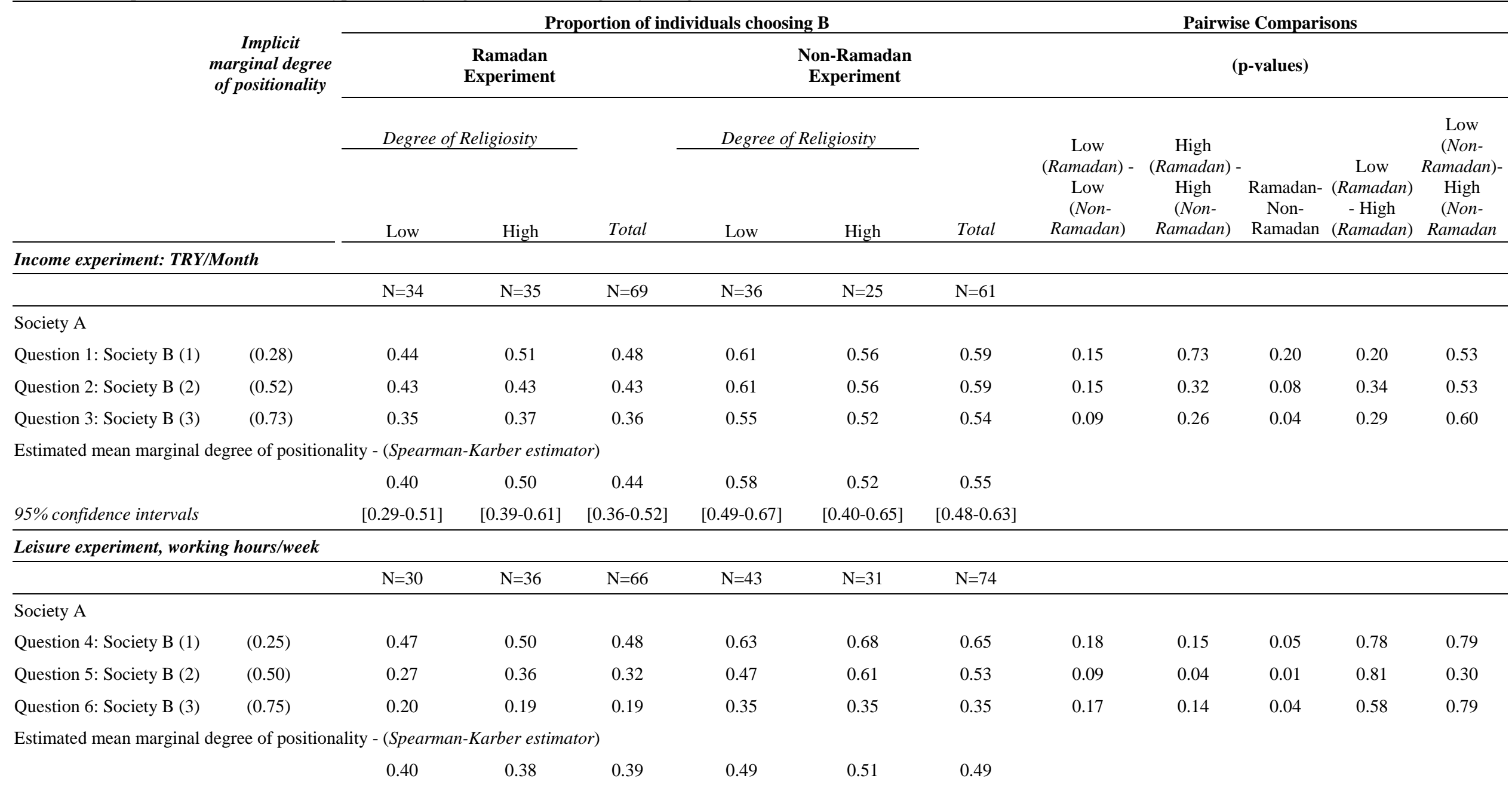




\section{$\mathrm{N}=42$}

$\mathrm{N}=24$

$\mathrm{N}=66$

Society A

Question 7: Society B (1)

Question 8: Society B (2)

(0.50)

\subsection{1}

0.65

Question 9: Society B (3)

(0.75)

0.46

0.42

0.56

0.63

0.67

0.62

0.58

0.46

0.32

0.37

0.48

0.46

$\begin{array}{ll}0.64 & 0.59 \\ 0.56 & 0.16 \\ 0.47 & 0.66\end{array}$

0.63

0.91

0.67

0.46

0.54

0.26

0.38

Estimated mean marginal degree of positionality - (Spearman-Karber estimator)

$\begin{array}{lll}0.48 & 0.52 & 0.50\end{array}$

0.56

0.46

0.53

95\% confidence intervals

[0.36-0.59]

[0.39-0.65] [0.41-0.58]

[0.46-0.66]

[0.30-0.63]

[0.44-0.61]

Note: The p-value is the probability value obtained from Mann-Whitney U test (Wilcoxon rank-sum test). N is the number of observations. Low means a low degree of religiosity and high means a high degree of religiosity. 


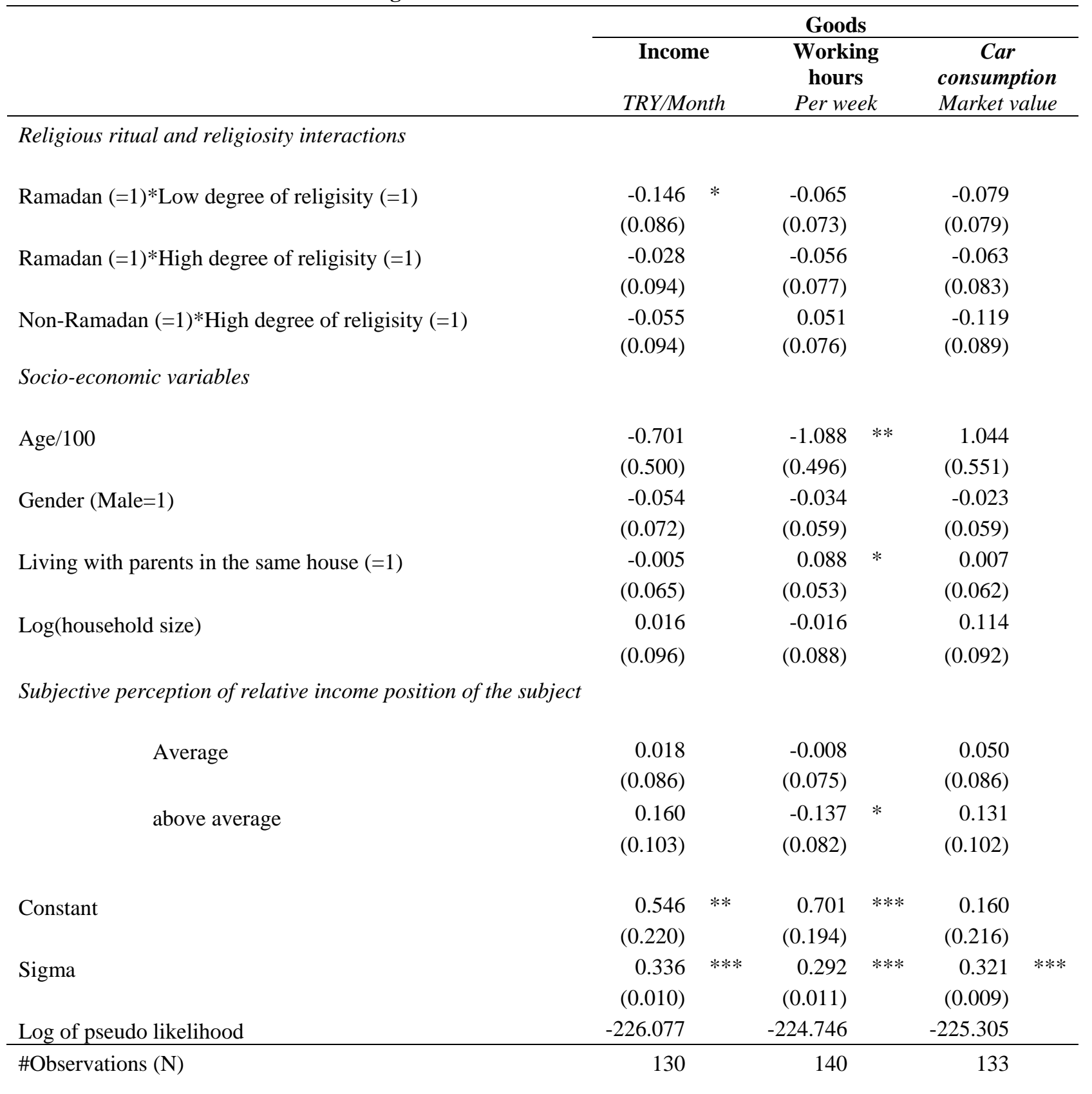

Notes: Robust standard errors are in parentheses. *, **, and *** indicate significance level at the 0.01, 0.05, and 0.10 levels. 